\title{
OAVAA \\ AIAA 96-2197 \\ Calibration of the Langley 8-Foot High Temperature Tunnel for Hypersonic Airbreathing Propulsion Testing
}

Lawrence D. Huebner, Kenneth E. Rock, Randall T. Voland, and Allan R. Wieting

NASA Langley Research Center Hampton, VA

\section{9th AIAA Advanced Measurement and Ground Testing Technology Conference June 17-20, 1996 / New Orleans, LA}




\title{
CALIBRATION OF THE LANGLEY 8-FOOT HIGH TEMPERATURE TUNNEL FOR HYPERSONIC AIRBREATHING PROPULSION TESTING
}

\author{
Lawrence D. Huebner*, Kenneth E. Rock ${ }^{\dagger}$, Randall T. Voland* and Allan R. Wieting ${ }^{\ddagger}$ \\ NASA Langley Research Center
}

\begin{abstract}
$\underline{\text { Abstract }}$
The NASA Langley 8-Foot High Temperature Tunnel has recently been modified to produce a unique testing capability for hypersonic airbreathing propulsion systems. Prior to these modifications, the facility was used primarily for aerothermal loads and structural verification testing at true flight total enthalpy conditions for Mach numbers between 6 and 7 . One of the recent modifications was an oxygen replenishment system which allows operating airbreathing propulsion systems to be tested at true flight total enthalpies. Following the modifications to the facility, calibration runs were performed at total enthalpies corresponding to flight Mach numbers of 6.3 and 6.8 to establish the flow characteristics of the facility with its new capabilities. The results of this calibration, as well as modifications to tunnel combustor hardware prior to calibration to improve tunnel flow quality, are described in this paper.
\end{abstract}

\begin{tabular}{|c|c|}
\hline \multicolumn{2}{|r|}{ Nomenclature } \\
\hline $\mathrm{c}$ & local speed of sound $(\mathrm{ft} / \mathrm{s})$ \\
\hline $\mathrm{H}_{\mathrm{t}}$ & total enthalpy (BTU/lbm) \\
\hline LOX & Liquid oxygen \\
\hline M & Mach number \\
\hline MW & molecular weight \\
\hline $\mathrm{p}$ & static pressure (psia) \\
\hline $\mathrm{p}^{\prime}$ & normalized pressure (see Figs. 5 and 8) \\
\hline$p_{t}$ & total pressure (psia) \\
\hline $\mathrm{p}_{\mathrm{t}, 2}$ & pitot pressure (psia) \\
\hline$S_{t}$ & total entropy (BTU/lbm) \\
\hline $\mathrm{T}$ & static temperature $\left({ }^{\circ} \mathrm{R}\right)$ \\
\hline $\mathrm{T}_{\mathrm{t}}$ & total temperature $\left({ }^{\circ} \mathrm{R}\right)$ \\
\hline $\mathrm{u}^{\prime}$ & normalized velocity (see Fig. 5) \\
\hline $\mathrm{U}$ & velocity (ft/s) \\
\hline$x_{i}$ & mole fraction of species i (see Table 6) \\
\hline $\mathrm{X}$ & lateral position from tunnel centerline (in) \\
\hline $\mathrm{Y}$ & $\begin{array}{l}\text { vertical position from tunnel centerline } \\
\text { (in) }\end{array}$ \\
\hline$\gamma$ & ratio of specific heats \\
\hline$\Delta$ & deviation from average flow value $(\%)$ \\
\hline$\theta$ & $\begin{array}{l}\text { flow survey apparatus rake sweep angle, } \\
\text { measured from the vertical (deg) }\end{array}$ \\
\hline$\rho$ & density $\left(\right.$ slugs $\left./ \mathrm{ft}^{3}\right)$ \\
\hline & freestream conditions \\
\hline
\end{tabular}

* Aerospace Engineer, Hypersonic Airbreathing Propulsion Branch, Gas Dynamics Division, MS 168, Hampton, VA 23681-0001, AIAA Senior Member.

$\dagger$ Aerospace Engineer, Hypersonic Airbreathing Propulsion Branch, Gas Dynamics Division, MS 168, Hampton, VA 23681-0001, AIAA Member.

$¥$ Assistant Chief, Gas Dynamics Division, MS 197, Hampton, VA 23681-0001, AIAA Associate Fellow.

\section{Introduction}

The NASA Langley 8-Foot High Temperature Tunnel ( 8 ' HTT) was designed in the late 1950's and placed into service in the mid 1960's as a facility to conduct aerothermal loads, aerothermostructures, and high-enthalpy aerodynamic research. ${ }^{1}$ The highenthalpy flow is produced by burning methane and air at high pressure in the facility combustor, then expanding the flow through an eight-foot exit-diameter hypersonic nozzle into the test section. These high-enthalpy combustion products contain very little available oxygen, so during the late 1980s and early 1990s the tunnel was modified with a liquid oxygen (LOX) injection system to replenish the oxygen consumed by the methane-air combustion process. ${ }^{2}$ This oxygen replenishment system, which became fully operational in 1993, enables the testing of large hypersonic airbreathing propulsion systems at flight enthalpies from Mach 4 to Mach 7.

LOX addition to the facility flow had a significant impact on the detailed characteristics of the test-section flowfield, requiring a flow quality improvement and calibration program which focused on two specific test conditions; both were run with a tunnel combustor pressure of 2000 psia, but with different combustor temperatures corresponding to Mach 6.3 and 6.8 flight total enthalpies. These conditions were chosen at the request of the National Aero-Space Plane (NASP) program for tests of the Concept Demonstration Engine (CDE), which were performed following this flow quality improvement and calibration program. ${ }^{3}$ The flow quality problems addressed were combustioninduced acoustic fluctuations and steady-state flow asymmetry.

This paper will discuss the facility characteristics and the flow quality improvements that were required

Copyright $\odot 1996$ by the American Institute of Aeronautics and Astronautics, Inc. No copyright is asserted in the United States under Title 17, U.S. Code. The U. S. Government has a royalty-free license to exercise all rights under the copyright claimed herein for Governmental purposes. All other rights are reserved by the copyright owner. 
for obtaining an acceptable test medium. Following this, documentation of the calibration of the $8^{\prime}$ HTT will be presented, including the tunnel conditions of interest, details of the instrumentation and acquired data, and an analysis of these data.

\section{Test Facility}

An aerial view of the NASA Langley 8-Foot High Temperature Tunnel and its ancillary equipment are shown in Figure 1. Air is stored at 6000 psia in 12 bottles with a total volume of 14,200 cubic feet housed in the large building shown on the right. The methane fuel is stored in the horizontal tanks on the left at 6000 psia. Oxygen is stored at low pressure in the 28,000 gallon LOX storage tank which feeds an 8,000 gallon LOX run tank capable of delivering $225 \mathrm{lbm} / \mathrm{s}$ at 2000 psia. The tunnel can operate at combustor total pressures up to 3500 psia, but the LOX run tank has a maximum working pressure of 2290 psia. Hydrogen, used to fuel the test articles, is stored in the $\mathrm{H}_{2}$ trailers at 2200 psia. A $20 \% / 80 \%$ molar mixture of silane and hydrogen is used as an ignition source for the hydrogen fuel, and is stored in a portable single trailer at 2300 psia. All waste gases are vented and combusted at the top of the flare stack.

A schematic representation of the $8^{\prime}$ HTT configured for airbreathing propulsion testing is shown in Figure 2. In the facility combustor, Figure 3, highpressure, ambient-temperature air enters through a torus at the upstream end of the combustor. To protect the carbon-steel pressure vessel from the hot combustion gases, the air flows in the annular space between the pressure vessel and the outer stainless steel liner to the downstream end of the combustor where it turns $180^{\circ}$ and flows back upstream in the annular space between the outer liner and an inner nickel 201 liner and enters the combustor at approximately the mid point of the combustor. The LOX injector ring is at the very end of the inner liner as shown in Figure 3. The LOX is injected at the beginning of a 20-inch-long annular space between the LOX ring and the outer liner where it mixes with the air. At this point, oxygen-enriched air flows into the area bounded by the outer liner, turns $180^{\circ}$, and flows downstream to the combustion zone. The resulting mixture is mixed and burned with methane which is delivered to the combustor through a methane fuel injector, consisting of 15 concentric rings of tubing and a total of 700 fuel ports (Figure 4). Tabs on the fuel injector rings generate vortices to promote flame stabilization. The combustion products create the test medium. The methane/air mass ratio can be varied to obtain total enthalpies simulating Mach 6-7 flight. Since this combustion process depletes some of the oxygen from the high pressure air, the levels of LOX are varied to provide an oxygen molar concentration in the test gas equal to that of air.

The high-pressure vitiated-air combustion products are expanded through a converging-diverging supersonic nozzle with a transpiration-cooled nozzle throat (Figure 3). This nozzle throat uses air for cooling and is the largest of its type. The transpiration cooled section of the nozzle has a maximum internal diameter of 36 inches, a throat diameter of 5.6 inches, and an overall length of 7.2 feet. The design consists of 8880 thin metal platelets of various thicknesses on which hydraulic passages are photoetched. The platelets are bonded in 16 sections. The injection slot size and mass flow of coolant are proportional to the local heat flux, providing adequate nozzle cooling without separating the nozzle throat boundary layer.

The flow then expands in the Mach 6.8 facility nozzle to an exit diameter of eight feet and exhausts into the free-jet test section. To facilitate starting the tunnel (establishing hypersonic flow) and to protect models from startup and shutdown dynamic loads, models are typically stored beneath the test section and inserted into the stream after steady-state hypersonic flow has been established (see Figure 2). A hydraulic elevator system inserts the model into the test section in as little as one second, subjecting the model to a maximum acceleration of $2 \mathrm{~g}$ 's during normal operation.

Downstream of the test section, the flow is captured by the diffuser collector ring and processed by a straight-pipe supersonic diffuser, pumped by an annular air ejector and mixing tube. Finally, the flow passes through a second minimum to bring it to subsonic speeds and exhaust it to the atmosphere. Run times are limited to approximately 30 seconds of on-point conditions due to constraints on high-pressure air storage, but test-article heating may limit run times as well.

\section{Flow Quality Improvement}

Initial attempts at establishing an acceptable flow in the $8^{\prime}$ HTT test section revealed numerous problems that existed in the combustor, including acoustic fluctuations and asymmetric test-section flow profiles. These problems as well as corrective actions to alleviate them are described below.

\section{Acoustic Fluctuations}

Prior to acoustic treatments the combustor had the acoustic characteristics of a closed-end organ pipe. These characteristics are defined by the lengths of the hot and cold gas sections and their respective sound speeds (Figure 5). This figure shows normalized values of static pressure and velocity fluctuations. The primary mode had a fundamental frequency of $28 \mathrm{~Hz}$. Pressure antinodes occurred at each end of the combustor, even though there is an opening at the throat. A pressure node occurred near the fuel injector; however, a velocity 
antinode also occurred here. This led to velocity fluctuations in the supply air which were large enough to momentarily reverse the flow, causing the flame to engulf the fuel injector and result in operation above $2000^{\circ} \mathrm{R}$. These fluctuations led to pressure fluctuations in the combustor on the order of \pm 70 psia (about the mean of 2000 psia) and pressure fluctuations in the test section. Test-section total temperature fluctuations were on the order of $300^{\circ} \mathrm{R}$ about the mean of $3560^{\circ} \mathrm{R}$.

In order to attenuate these fluctuations, a resonator system consisting of a head-end Helmholtz resonator and baffle plate were added to the combustor hardware (Figure 6). The Helmholtz resonator, tuned to $28 \mathrm{~Hz}$, was located 47 inches from the closure plug, creating the necessary resonator cavity. Thirty-six one-inch diameter tubes that are 4 inches long penetrate the plate. These tubes along with the perimeter clearance formed the required acoustic impedance. A 7-percent-porosity baffle plate was added at the downstream end of the LOX injector ring to help alleviate many of the combustor flow disturbances caused by flow turning and internal hardware. The baffle plate acoustically appears as a solid wall and sets up a similar standing wave to the original configuration. However, in the new configuration, the pressure node and velocity antinode are downstream, and not upstream, of the fuel injector.

After the resonator system was installed, acoustic power absorption was significantly improved, as evidenced by unsteady pressure measurements in the combustor and test section. As shown in Figure 7, the calculated resonator absorption characteristics were considered good near $28 \mathrm{~Hz}$, but the baffle was found to have a broad absorption power spectrum from 10 to 90 $\mathrm{Hz}$, especially when the flow of air through the baffle was considered. The combined resonator/baffle system worked very well; unsteady pressure data (Figure 8) showed that the peak-to-peak pressure levels were reduced from about 70 psia at $28 \mathrm{~Hz}$ to less than 5 psia at about $300 \mathrm{~Hz}$. These low pressure fluctuations indicate similarly low velocity fluctuations. The fuel injector rings now operate below $800^{\circ} \mathrm{R}$, a $1200^{\circ}$ difference with respect to the original configuration, indicating that the velocity fluctuations are less than the mean flow velocity. This reduced operating temperature level means increased injector life and makes the injector an unlikely ignition source for unburned gases, yielding a significant improvement in facility operability, productivity, and safety.

\section{Asymmetric Test-Section Flow Profiles}

The addition of LOX to the combustion air to replenish the oxygen consumed during combustion, appeared to accentuate existing temperature gradients in the combustor. Locally fuel rich regions burned hotter, while lean regions remained cold, due to the addition of the extra oxygen. These increased temperature gradients, as well as the low combustor flow velocities ( $5 \mathrm{ft} / \mathrm{s}$ cold section, $40 \mathrm{ft} / \mathrm{s}$ hot section) and long length of the combustor (approximately $15 \mathrm{ft}$ each in the hot and cold sections), set up a buoyancy driven flow circulation in the combustor. This circulation produced a non-uniform temperature field entering the facility nozzle, which resulted in non-uniform temperature and pressure profiles in the test section. While the pressure at the facility nozzle entrance was uniform, the exit pressure was non-uniform due to condensation of water vapor in the cooler regions of the flowfield during the nozzle expansion process. Predictions had been made of the amount and effects of water vapor condensation during the nozzle expansion process at various test conditions in both 1-D and axisymmetric calculations $^{4,5}$, so the trends of lower Mach number and pitot pressure in the areas where condensation occurred were as expected.

A computational study with a compressible lowspeed Navier-Stokes code was used to provide a fundamental understanding of the major influence the buoyancy forces had on the combustor flow and insight into corrective actions. This study revealed the sources of global nonuniformities, which were identified as the unheated air that passed between the outer injector ring and the inner liner (25\% of the total air flow) as well as the air flow along the centerline core and the three inner rings. (Refer to Figure 4.)

Global nonuniformities. Initially fuel was not injected from the outer ring to avoid hot-gas proximity to the combustor inner liner, which would lead to excessive inner liner temperatures and reduced liner life. Fuel was not injected from the inner three rings because they were not used as part of the original methane/air fuel injector. Sufficient fuel was injected from the remaining rings to obtain the desired global fuel-air ratio. This global fueling approach, while acceptable with methane and air, proved inadequate with the addition of the LOX capability. Apparently, the buoyancy forces moved the colder air away faster than the fuel could diffuse into these remote areas.

Sufficient fuel mixing was achieved by adding fuel injection ports to all rings except the outer-most ring, with a relatively uniform spacing of approximately 2 inches between ports. This ring could not be used for fuel without adding distribution lines to route the fuel to the ring. Hence, fuel-port holes were angled outward to distribute fuel into this area. Angles of $10^{\circ}, 20^{\circ}$, and $40^{\circ}$ were tested, all of which worked well relative to obtaining the desired fuel-to-air ratio in this region. However, the larger angles led to flame impingement on the liner and caused liner overheating. Thus, the final configuration used fuel ports angled outward at $10^{\circ}$ on the outer ring. The three inner rings were similarly modified, and the inner-most ring had fuel-port holes 
angled $60^{\circ}$ toward the centerline. These modifications resulted in the desired fuel-air ratio and eliminated the cold center core.

Local nonuniformities. Elimination of these global nonuniformities revealed various local nonuniformities. The test-section pitot-pressure contours revealed twin hot spots that originated from the methane supply line manifolds, which are located just downstream of the baffle plate. The proximity of the fuel injector rings to the baffle plate ( 27 inches) proved to be inadequate to allow the air jets to coalesce so as to provide a uniform flow. The lack of air in this region led to a fuel-rich zone and the resulting hot spots. The desired fuel-air ratio was achieved by routing air to the flange wakes and closing some of the fuel injection ports in the wake of the flanges and in the wake of the spokes, as shown in Figure 9.

Following the elimination of the nonuniformities, the test-section flow uniformity was significantly improved with the exception of the lower portion of the test core, which was still cooler than the surroundings and promoted buoyant flow circulation, resulting in the hot core rising to the top. This was alleviated by decreasing the air flow in the bottom of the baffle, hence increasing the fuel-air ratio.

\section{$8^{\prime}$ HTT Facility Nozzle Calibration}

After the flow quality was considered acceptable, a series of runs were conducted in the $8^{\prime}$ HTT to obtain more detailed measurements to quantify and evaluate the characteristics of the facility flow delivered to the test section. Measurements acquired just downstream of the facility nozzle exit included pitot and static pressures, total temperatures, and oxygen concentration measurements. Measurements of the complete gas composition were obtained using a separate rake along the vertical centerline of the nozzle near the midway point of the test section.

\section{Instrumentation}

Physical data acquired for quantifying tunnel flow conditions consisted of static and pitot pressures and total temperatures measured on a flow survey apparatus (FSA) rake that swept out a circular arc sector in the test section. Figure 10 shows a sketch of the instrumentation locations for the FSA. The solid symbols refer to instrumentation that exists on the FSA rake. In general, the spacing between similar probes is six inches. The three probe types have been isolated on three different rays, designating three of the five angular positions at which data were recorded. These angles were $+12,+6,0,-6$, and -12 degrees relative to the vertical centerline. In addition to the pressure and temperature probes, two zirconium-oxide oxygen sensors were mounted to gas sample tubes on the side of the FSA rake to determine the off-centerline oxygen concentration. The FSA rake was positioned 18 inches downstream of the facility nozzle exit and swept into the flow once the proper tunnel conditions were established. The first angular position was held for about five seconds to allow the measured data to settle; the positions for the other angles were held for about three seconds. The 13 pitot and 11 static pressure ports were connected to individual pressure transducers mounted to the FSA rake. The 13 total temperatures were measured with iridium/iridium $40 \%$-rhodium thermocouples.

Chemical composition data were acquired via gas samples along the vertical centerline of the tunnel, captured by a 12-probe rake mounted near the streamwise middle of the test section. The rake was injected into the flow following supersonic flow establishment in the test section. The position of the gas-sample probes are shown in Figure 10 by the open triangles. These samples were captured in gas bottles and analyzed after each run by gas chromatography to determine the mole fractions of oxygen, nitrogen, carbon dioxide, water, argon, carbon monoxide and total hydrocarbons.

\section{Test Conditions and Flow Quality Criteria}

This calibration of the 8'HTT for hypersonic propulsion testing was performed in August 1993. The nominal stagnation conditions for the Mach 6.3 test point were a total combustor pressure of 2000 psia and a total temperature of $3000^{\circ} \mathrm{R}$. The nominal stagnation conditions for the Mach 6.8 test point were a total combustor pressure of 2000 psia and a total temperature of $3560^{\circ} \mathrm{R}$. As stated earlier, these conditions were requested by the NASP program for tests of the CDE. Flow quality criteria for the flow captured by the CDE were also supplied by the NASP program. The criteria were that pressure and temperature measurements were within five percent of the average value and that the Mach number was within two percent of the average Mach number. The final criterion was that the oxygen levels exist within \pm 0.01 mole fraction about the nominal oxygen level for air of 0.21 . These criteria were met for the capture area of the CDE. ${ }^{3}$

For the purposes of this paper, these same criteria are applied to four different generic areas that represent potential flow capture areas for hypersonic airbreathing engines. These areas, shown in Figure 11, are all centered at the tunnel centerline and are designated Box 1 through Box 4. Box 1 has the smallest capture area. Boxes 2 and 3 are horizontally wide and vertically tall capture areas, respectively. Box 4 is a four-foot square capture area. These flow quality criteria will be studied for each capture area for both test conditions.

Two runs were completed at each of the Mach 6.3 and Mach 6.8 test conditions. Table 1 identifies the run numbers, Mach numbers, and FSA rake position angles that were achieved for these runs. 
Table 1: Tunnel Calibration Runs.

\begin{tabular}{|c|c|c|}
\hline Run & $\mathrm{M}_{\infty}$ & FSA Rake Positions (deg) \\
\hline \hline 120 & 6.3 & $12.4,7.5,1.4,-5.5,-12.9,-20.4$ \\
\hline 123 & 6.3 & $12.0,6.7,0.2,-6.2,-12.5$ \\
\hline 125 & 6.8 & $11.6,6.7,0.6,-5.9,-12.3$ \\
\hline 126 & 6.8 & $12.6,8.4,3.0,-3.2,-8.9$ \\
\hline
\end{tabular}

\section{Calibration Analysis Methodology}

Calculation of the flow quantities in the FSA rake plane located eighteen inches from the facility nozzle exit was accomplished using a multi-step procedure. The measured total temperature probe data were corrected for environmental heat losses, after which all probe data were normalized to the nominal tunnel operating condition for each test point. The individual pitot pressure, static pressure, and total temperature data were then interpolated onto a common computational grid so that the remaining flow properties could be computed at each grid location. This computation was completed with the additional gas composition information from the gas sample measurements and an appropriate thermodynamic flow model.

The total temperature data were adjusted as follows to account for environmental (probe) losses:

$$
\mathrm{T}_{\mathrm{t} \text {, corr }}=\mathrm{T}_{\mathrm{t} \text {, raw }}+\mathrm{T}_{\text {offset }} \text {, }
$$

where $\mathrm{T}_{\text {offset }}=70^{\circ} \mathrm{R}$ for the Mach 6.3 condition and $\mathrm{T}_{\text {offset }}=160^{\circ} \mathrm{R}$ for the Mach 6.8 condition. In order to remove the slight fluctuations in tunnel conditions, the data were normalized as follows:

$$
\begin{aligned}
& \mathrm{T}_{\mathrm{t}, \text { norm,corr }}=\mathrm{T}_{\mathrm{t}, \text { corr }} \times \frac{\mathrm{T}_{\text {nominal }}}{\mathrm{T}_{\text {stag, ave }}+\mathrm{T}_{\text {stag, offset }}}, \\
& \mathrm{p}_{\mathrm{t}_{2}, \text { norm }}=\mathrm{p}_{\mathrm{t}_{2} \text {, raw }} \times \frac{2000}{\mathrm{PT} 3054}, \\
& \mathrm{p}_{\text {, norm }}=\mathrm{p}_{\text {raw }} \times \frac{2000}{\mathrm{PT} 3054},
\end{aligned}
$$

where $\mathrm{T}_{\text {stag,ave }}$ is the average of five combustor temperatures, PT3054 is the combustor total pressure, and $T_{t, \text { corr }}$ is as defined in Eq. 1. The values of the nominal tunnel temperature, $\mathrm{T}_{\text {nominal }}$, and the probe loss correction to stagnation temperature, $\mathrm{T}_{\text {stag,offset, }}$ are specific for the two test conditions as follows: for Mach $6.3, \mathrm{~T}_{\text {nominal }}=3000^{\circ} \mathrm{R}$ and $\mathrm{T}_{\text {stag, offset }}=235^{\circ} \mathrm{R}$. For Mach 6.8, $\mathrm{T}_{\text {nominal }}=3560^{\circ} \mathrm{R}$ and $\mathrm{T}_{\text {stag, offset }}=260^{\circ} \mathrm{R}$.

The corrected and normalized rake data were then interpolated onto a common computational grid. Both the Mach 6.3 and Mach 6.8 calibration data set were acquired from two separate tunnel runs in which multiple rake positions where achieved. The run numbers and rake positions for each calibration run is listed in Table 1. The Mach 6.3 data set is comprised of nine separate rake positions where pitot pressure and total temperature measurements were taken at 117 unique locations and static pressure measurements were taken at 99 locations. The Mach 6.8 data set is comprised of eight rake positions resulting in 104 pitot pressure and total temperature measurements and 88 static pressure measurements. Each data set was interpolated onto a grid with one-inch square grid spacing, allowing thermodynamic calculations to be made at each grid point location.

The vitiated test medium gas composition was inferred from the gas chromatography analysis. The experimentally quantified elemental species, namely the atomic nitrogen, oxygen, hydrogen, carbon, hydrogen, and argon were spatially averaged to conserve the relative mass ratios. This elemental composition, in conjunction with the local static temperature and pressure, was used to determine the equilibrium thermodynamic properties and composition.

The stagnation probe flow model is depicted in Figure 12. The local freestream static pressure and temperature were calculated using an iterative procedure where the freestream flow is assumed to be in equilibrium, the flow process across the probe-induced normal shock is modeled as molecularly frozen, and the subsequent stagnation process to the probe tip is modeled as equilibrium flow where the composition of the stagnated gas is defined by the pitot pressure and probe total temperature.

\section{Calibration Results}

As stated above, the flow composition must be known to accurately calculate flow quantities derived from the pitot pressure, static pressure, and total temperature measurements. Table 2 lists the average flow composition used in the data analysis for both test conditions. The listed values are the average composition of the gas samples taken in the core flow ( \pm 12 inches from centerline), for both calibration runs at each test condition. Although carbon monoxide and unburned hydrocarbons were also measured, none were

Table 2: Nozzle-exit gas composition mole fraction.

\begin{tabular}{|l||c|c|}
\hline $\mathrm{M}_{\infty}$ & 6.3 & 6.8 \\
\hline \hline $\mathrm{x}_{\mathrm{O}_{2}}$ & 0.2031 & 0.2079 \\
\hline $\mathrm{x}_{\mathrm{N}_{2}}$ & 0.5723 & 0.5127 \\
\hline $\mathrm{x}_{\mathrm{CO}_{2}}$ & 0.0725 & 0.0910 \\
\hline $\mathrm{x}_{\mathrm{H}_{2} \mathrm{O}}$ & 0.1449 & 0.1820 \\
\hline $\mathrm{x}_{\mathrm{Ar}}$ & 0.0072 & 0.0064 \\
\hline
\end{tabular}


detected. While the gas samples were only obtained on the vertical centerline, the oxygen levels measured offcenterline by the zirconium-oxide sensors generally matched the oxygen levels measured on centerline by the gas samples and did not vary much off-centerline. Therefore, it was assumed that the composition was horizontally uniform.

Results of the 8' HTT flow calibration are presented in Figures 13-15 for the Mach 6.3 condition and Figures 16-18 for the Mach 6.8 condition. The contour data were obtained at an axial location 18 inches downstream of the end of the facility nozzle and is presented such that the reader is looking upstream. The contour regions presented in the test core contour plots (Figures 13 and 16) correspond to the extent that the circular arc sector was traversed by the FSA rake. The test-core, percentdeviation contour plots (Figures 14 and 17) include outlines of the Box 2 and Box 3 capture areas. The Box 1 capture area is the intersection of these two outlines, and the Box 4 capture area is essentially the entire plot $( \pm 24$ inches in the vertical and horizontal directions from the center of the tunnel). Oxygen concentration data from the centerline gas sample probes are presented in Figures 15 and 18.

Results at Mach 6.3. Contours of measured pitot pressure, corrected total temperature, and static pressure are shown in Figures 13a, b, and c, respectively. It can be seen by comparing pitot pressure and total temperature that regions of high pitot pressure are accompanied by regions of high total temperature. This is a result of water vapor condensing in low temperature regions of the flow and driving the pitot pressure down as described previously. The highest temperature pocket appears in the lower left side. The static pressure plot (Figure 13c) shows a relatively uniform region surrounding the tunnel centerline. The calculated Mach number contour (Figure 13d) mimics the shape of the pitot contour. It should be noted that the average Mach number in this case is approximately 6.3, even though the flow has been expanded through a nominal Mach 7 nozzle. This result is due to condensation of water vapor during the expansion process. The total temperature at this test condition, $3000^{\circ} \mathrm{R}$, is low enough that significant amounts of condensation occur throughout the flow, resulting in a globally lower Mach number and high total pressure losses.

Contours of percent deviation from the average pitot pressure, corrected total temperature, and calculated Mach number are shown in Figures 14a, b, and c, respectively. For the most part, the differences in pitot pressure and total temperature are within five percent of the average, except near the top center and lower left of the Box 1 capture area. Box 2 deviation is the next best, with no additional variations larger than four percent in the extended horizontal regions. More deviation is seen for Box 3 , especially at the extremes of the vertical extents where deviations exceed 20 percent. As expected, Box 4 possesses the worst uniformity. The Mach number differences are typically less than two percent, except in the areas where pitot pressure and total temperature were significantly different than the average, as discussed above.

The final criterion was that oxygen concentration mole fraction levels were within 0.01 of the nominal oxygen content in air, namely 0.21 . Figure 15 shows that for the two runs that were analyzed at this condition, the oxygen concentration was between 0.20 and 0.22 within the Box 1 and Box 2 capture areas, but falls off above them.

Results at Mach 6.8. At Mach 6.8 the data indicate a region of fairly uniform flow near the centerline of the facility. This uniform test region corresponds closely to the Box 2 capture area as evidenced by the pitot pressure, total temperature and Mach number contours (Figures 16a, b, and d). In this case the total temperature is high enough that it appears that only localized condensation is occurring. The static pressure contour plot (Figure 16c) appears less uniform; however, the minimum and maximum contour levels on this plot differ by only $0.04 \mathrm{psi}$. The results of the percent deviation in the test core conditions were determined (Figures 17a-c) and were very similar to the results obtained at Mach 6.3.

Similar to the results from the Mach 6.3 oxygen concentrations, Figure 18 shows that centerline oxygen concentration was between 0.20 and 0.22 mole fraction within the Box 1 and Box 2 capture areas, but is low above them.

Calibration Summary. Tables 3 and 4 present a summary of the stream-thrust-averaged quantities and equivalent one-dimensional properties where mass, momentum, and energy are conserved, respectively. These calculations were made for the four capture areas at Mach 6.3, using the analysis methodology previously discussed and an enthalpy base consistent with that of Reference 6. Note the similarity of the averaged conditions for Boxes 1 and 2, as well as the deviation when the capture areas of Boxes 3 and 4 are included. Tables 5 and 6 present the same information for the Mach 6.8 condition.

\section{Concluding Remarks}

The NASA Langley Research Center 8-Foot High Temperature Tunnel has been modified to allow the testing of hypersonic airbreathing propulsion systems at true flight enthalpy conditions. The unique design of the current facility configuration has been described, including the oxygen enrichment and hydrogen fuel 
Table 3: Mach 6.3 stream-thrust-averaged integrated flow conditions.

\begin{tabular}{|l||r|r|r|r|}
\hline & \multicolumn{1}{||}{ Box 1 } & \multicolumn{1}{c|}{ Box 2 } & \multicolumn{1}{c|}{ Box 3 } & Box 4 \\
\hline \hline $\mathrm{p}_{\mathrm{t}, 2}$ & 16.31 & 16.26 & 15.81 & 15.67 \\
\hline $\mathrm{T}_{\mathrm{t}, 2}$ & 2893. & 2890. & 2815. & 2814. \\
\hline $\mathrm{H}_{\mathrm{t}}$ & -484.6 & -485.9 & -511.0 & -511.4 \\
\hline $\mathrm{p}_{\mathrm{t}}$ & 1114. & 1099. & 1041. & 1014. \\
\hline $\mathrm{p}$ & 0.313 & 0.313 & 0.308 & 0.308 \\
\hline $\mathrm{M}_{\infty}$ & 6.32 & 6.31 & 6.26 & 6.24 \\
\hline
\end{tabular}

Table 4: Equivalent one-dimensional properties of the Mach 6.3 integrated flowfield.

\begin{tabular}{|l||r|r|r|r|}
\hline & \multicolumn{1}{|c|}{ Box 1 } & \multicolumn{1}{c|}{ Box 2 } & \multicolumn{1}{c|}{ Box 3 } & \multicolumn{1}{c|}{ Box 4 } \\
\hline \hline $\mathrm{T}_{\infty}$ & 391. & 391. & 390. & 391. \\
\hline $\mathrm{p}_{\infty}$ & 0.314 & 0.314 & 0.315 & 0.312 \\
\hline $\mathrm{H}_{\mathrm{t}}$ & -1231. & -1231. & -1231. & -1231. \\
\hline $\mathrm{S}_{\mathrm{t}}$ & 1.910 & 1.910 & 1.910 & 1.911 \\
\hline$\rho_{\infty}$ & $6.637 \times 10^{-5}$ & $6.632 \times 10^{-5}$ & $6.660 \times 10^{-5}$ & $6.605 \times 10^{-5}$ \\
\hline $\mathrm{MW}$ & 28.56 & 28.56 & 28.56 & 28.56 \\
\hline$\gamma$ & 1.38 & 1.38 & 1.38 & 1.38 \\
\hline $\mathrm{M}_{\infty}$ & 6.31 & 6.30 & 6.19 & 6.18 \\
\hline $\mathrm{U}_{\infty}$ & 6112. & 6107. & 5993. & 5994. \\
\hline $\mathrm{c}_{\infty}$ & 969. & 970. & 969. & 969. \\
\hline $\mathrm{T}_{\mathrm{t}, \infty}$ & 2894. & 2890. & 2809. & 2809. \\
\hline $\mathrm{p}_{\mathrm{t}, \infty}$ & 1099. & 1088. & 954.5 & 945.0 \\
\hline $\mathrm{p}_{\mathrm{t}, 2}$ & 16.26 & 16.22 & 15.69 & 15.56 \\
\hline
\end{tabular}

Table 5: Mach 6.8 stream-thrust-averaged integrated flow conditions.

\begin{tabular}{|l||r|r|r|r|}
\hline & \multicolumn{1}{||}{ Box 1 } & \multicolumn{1}{c|}{ Box 2 } & \multicolumn{1}{c|}{ Box 3 } & \multicolumn{1}{c|}{ Box 4 } \\
\hline \hline $\mathrm{p}_{\mathrm{t}, 2}$ & 16.95 & 16.88 & 16.35 & 16.15 \\
\hline $\mathrm{T}_{\mathrm{t}, 2}$ & 3578. & 3546. & 3492. & 3461. \\
\hline $\mathrm{H}_{\mathrm{t}}$ & -238.0 & -250.4 & -269.9 & -281.5 \\
\hline $\mathrm{p}_{\mathrm{t}}$ & 1804. & 1746. & 1652. & 1583. \\
\hline $\mathrm{p}$ & 0.283 & 0.285 & 0.279 & 0.279 \\
\hline $\mathrm{M}_{\infty}$ & 6.75 & 6.72 & 6.67 & 6.63 \\
\hline
\end{tabular}

systems. Flow-quality problems in the facility were identified and resolved, including acoustic fluctuations and asymmetric test-section flow profiles. Tunnel calibrations at total enthalpies representative of flight Mach numbers of 6.3 and 6.8 were discussed and showed a relatively uniform test core flow for a capture area approximately four feet wide by two feet high.
Table 6: Equivalent one-dimensional properties of the Mach 6.8 integrated flowfield.

\begin{tabular}{|l||r|r|r|r|}
\hline & \multicolumn{1}{|c|}{ Box 1 } & \multicolumn{1}{c|}{ Box 2 } & \multicolumn{1}{c|}{ Box 3 } & \multicolumn{1}{c|}{ Box 4 } \\
\hline \hline $\mathrm{T}_{\infty}$ & 449. & 448. & 450. & 450. \\
\hline $\mathrm{p}_{\infty}$ & 0.283 & 0.285 & 0.283 & 0.283 \\
\hline $\mathrm{H}_{\mathrm{t}}$ & -1216. & -1217. & -1216. & -1216. \\
\hline $\mathrm{S}_{\mathrm{t}}$ & 1.952 & 1.951 & 1.953 & 1.953 \\
\hline$\rho_{\infty}$ & $5.217 \times 10^{-5}$ & $5.263 \times 10^{-5}$ & $5.195 \times 10^{-5}$ & $5.192 \times 10^{-5}$ \\
\hline $\mathrm{MW}$ & 28.56 & 28.56 & 28.56 & 28.56 \\
\hline$\gamma$ & 1.38 & 1.38 & 1.38 & 1.38 \\
\hline $\mathrm{M}_{\infty}$ & 6.75 & 6.71 & 6.62 & 6.58 \\
\hline $\mathrm{U}_{\infty}$ & 6999. & 6955. & 6875. & 6832. \\
\hline $\mathrm{c}_{\infty}$ & 1037. & 1036. & 1039. & 1039. \\
\hline $\mathrm{T}_{\mathrm{t}, \infty}$ & 3595. & 3561. & 3501. & 3469. \\
\hline $\mathrm{p}_{\mathrm{t}, \infty}$ & 1793. & 1729. & 1543. & 1469. \\
\hline $\mathrm{p}_{\mathrm{t}, 2}$ & 16.80 & 16.73 & 16.14 & 15.93 \\
\hline
\end{tabular}

Tabular data of average flow conditions and onedimensional equivalent properties were presented for both test conditions.

\section{References}

1. Howell, R. R.; and Hunt, L. R.: "Methane-Air Combustion Gases as an Aerodynamic Test Medium." Journal of Spacecraft, Vol. 9, No. 1, January 1972, pp. 7-12.

2. Reubush, D. E.; Puster, R. L.; and Kelly, H. N.: "Modification to the Langley 8-Foot High Temperature Tunnel for Hypersonic Propulsion Testing," AIAA Paper 87-1887, June 1987.

3. Phelps, D. C.; McVey, W. J.; and Faulkner, R. F.: National Aerospace Plane Concept Demonstration Engine Final Test Report $(U)$. NASP Report X30SP94007, January 1995. (SECRET)

4. Erickson, W. D.; Hall, G. H.; and Prabhu, R. K.: Finite-Rate Water Condensation in CombustionHeated Wind Tunnels. NASA TN-2833, 1988.

5. Perrell, E. R.: Computation of Combustion Heated Hypersonic Wind Tunnel Flows in Phase Nonequilibrium, Ph.D. Thesis, North Carolina State University, 1994.

6. McBride, B. J.; Heimel, S.; Ehlers J. G.; and Gordon, S.: Thermodynamic Properties to $6000^{\circ} \mathrm{K}$ for 210 Substances Involving the First 18 Elements. NASA SP-3001, 1963. 


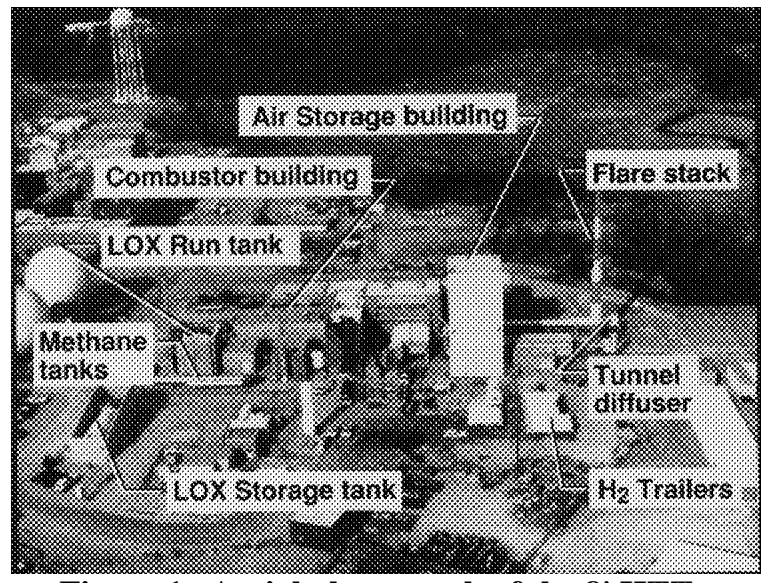

Figure 1. Aerial photograph of the 8' HTT.

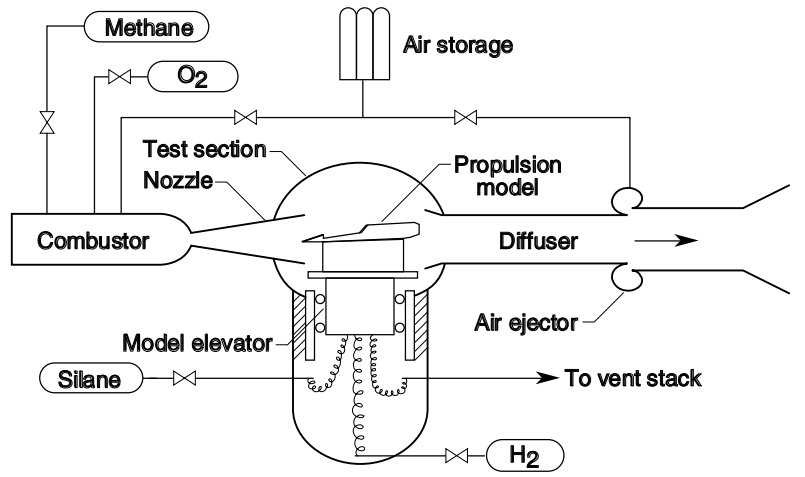

Figure 2. Schematic drawing of the 8' HTT for airbreathing propulsion testing.

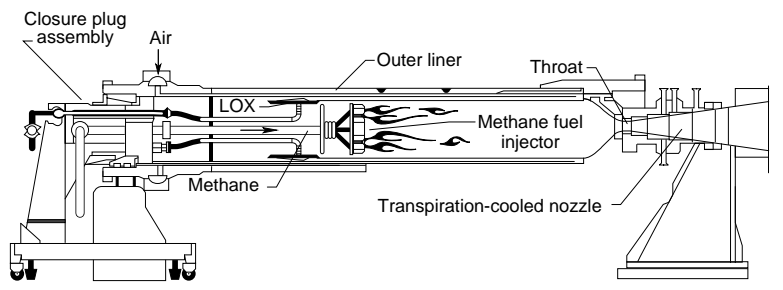

Figure 3. Schematic drawing of the 8' HTT combustor.

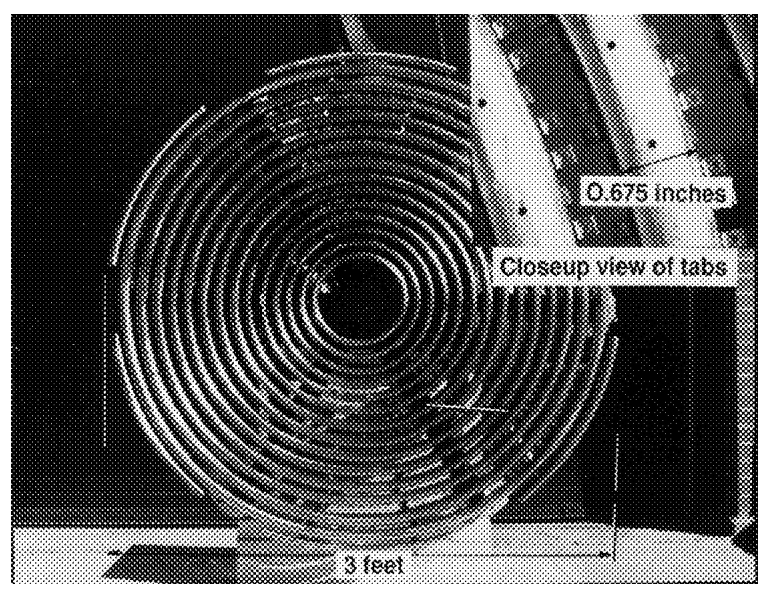

Figure 4. Fuel injector with combustion stabilizing tabs.

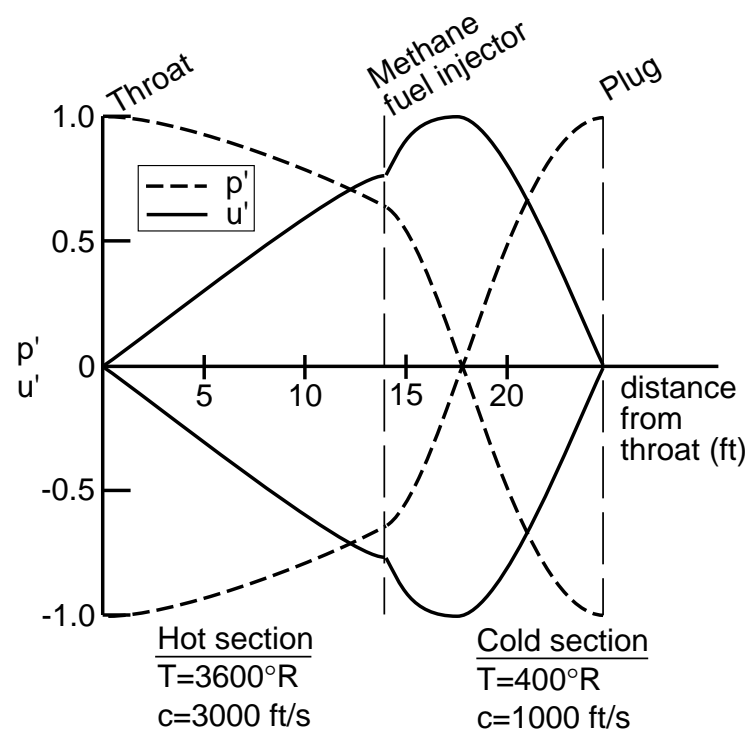

Figure 5. Normalized static pressure and velocity fluctuations in combustor due to acoustic standing wave.

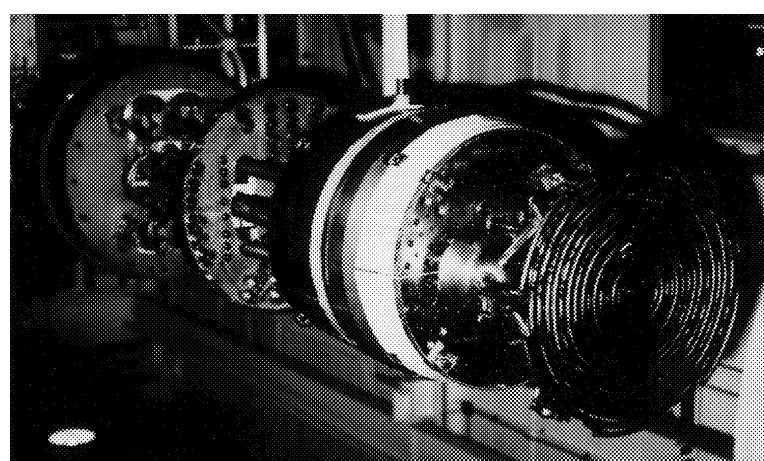

Figure 6. Fuel injection ring, baffle plate, and Helmholtz resonator assembly.

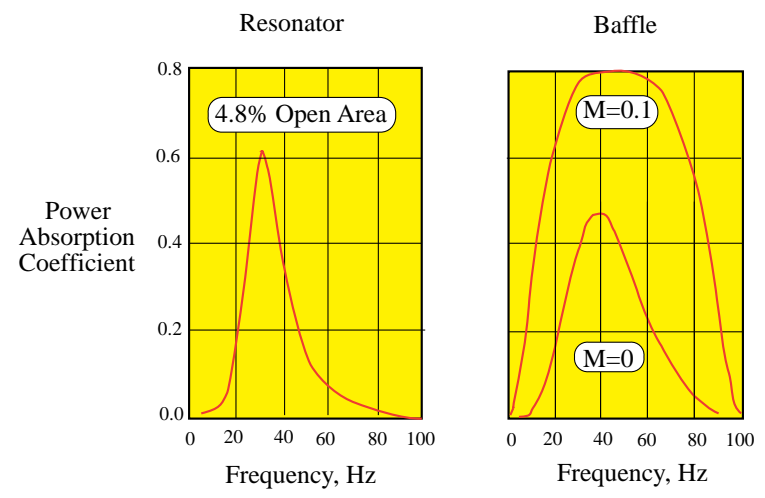

Figure 7. Calculated acoustic characteristics of resonator and baffle. 


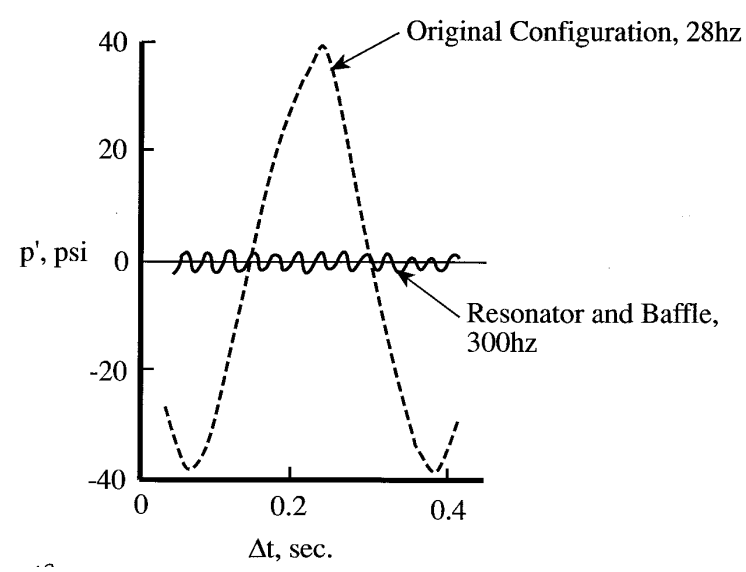

Figure 8. Typical unsteady pressure response in 8 ' HTT combustor in original configuration and after installation of resonator system.

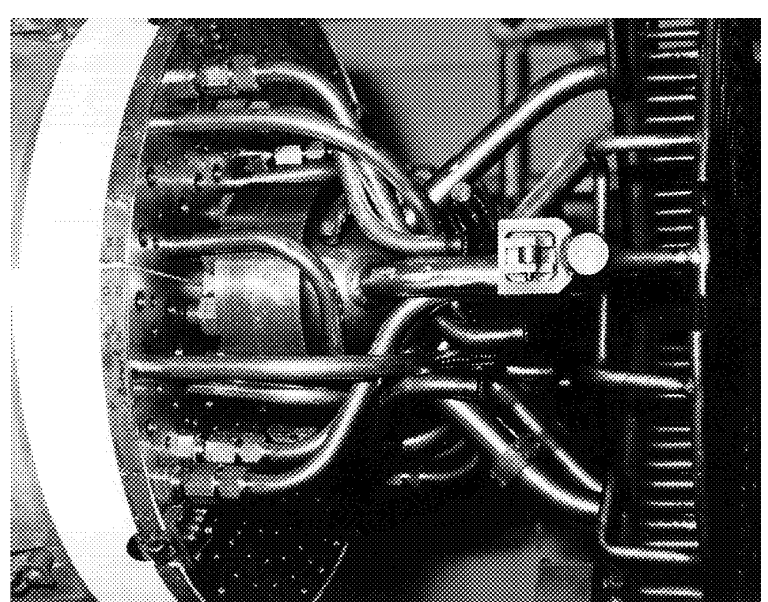

Figure 9. Photograph showing air tubes used to route flow around methane flanges.

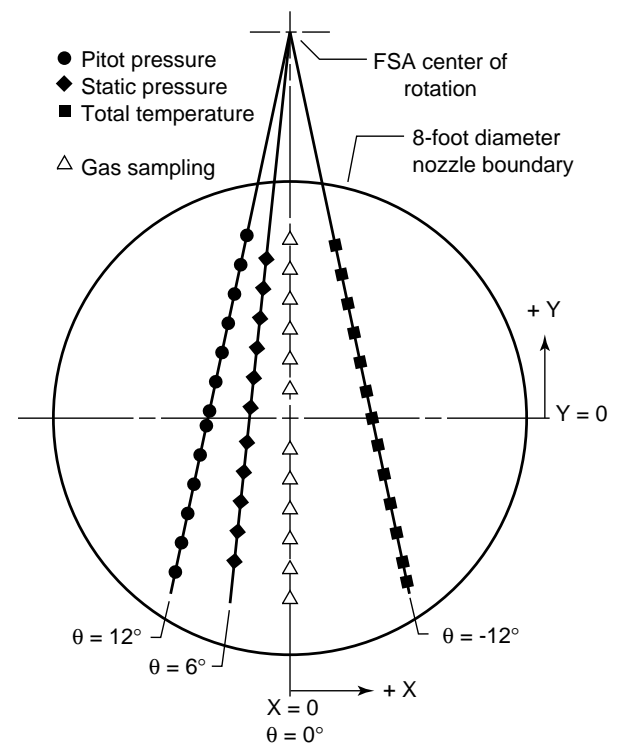

Figure 10. Instrumentation locations anc tunnel coordinate identification.

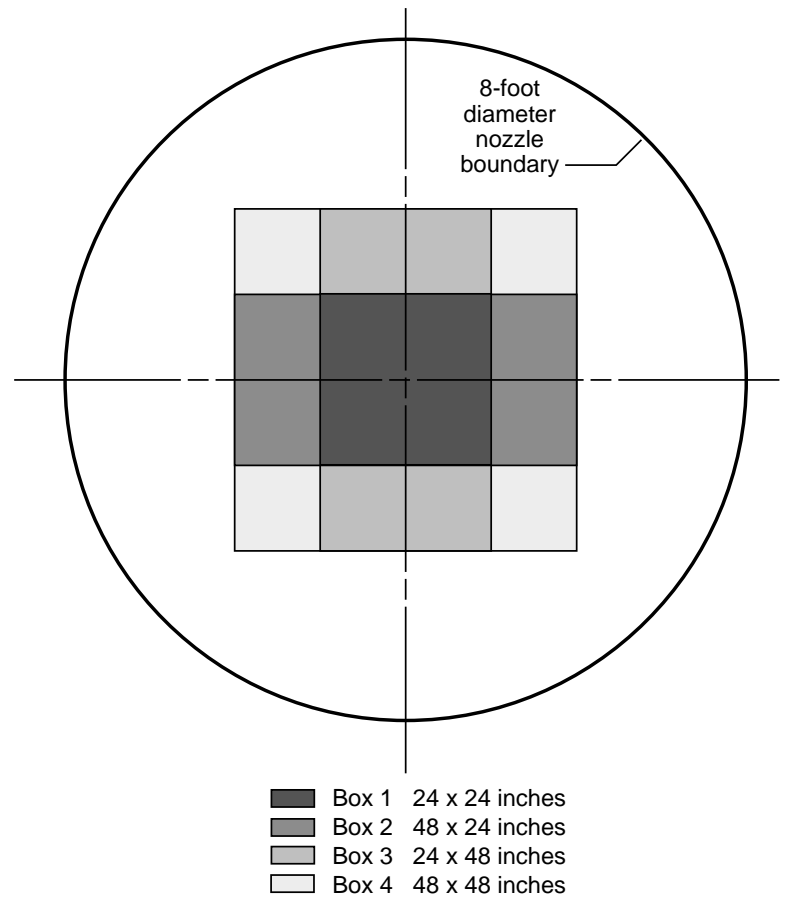

Figure 11. Identificaton of flow capture areas used in this calibration.

Measured quantities:

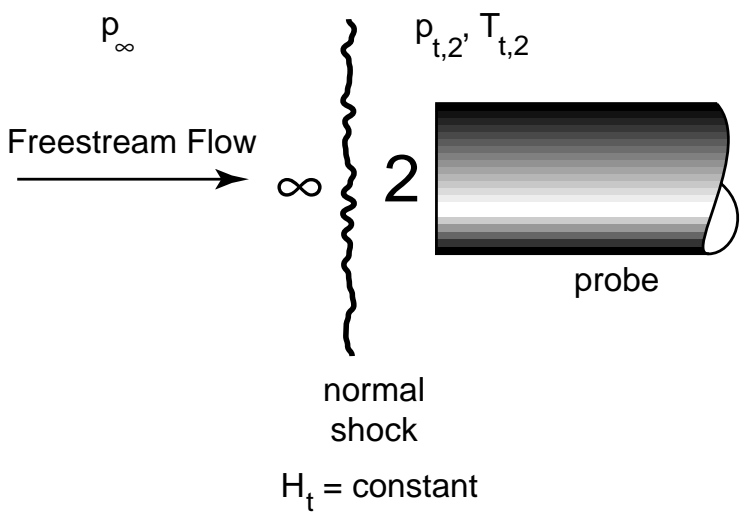

Flow assumption:

$$
\text { equilibrium frozen equilibrium }
$$

Figure 12. Stagnation probe-flow model. 


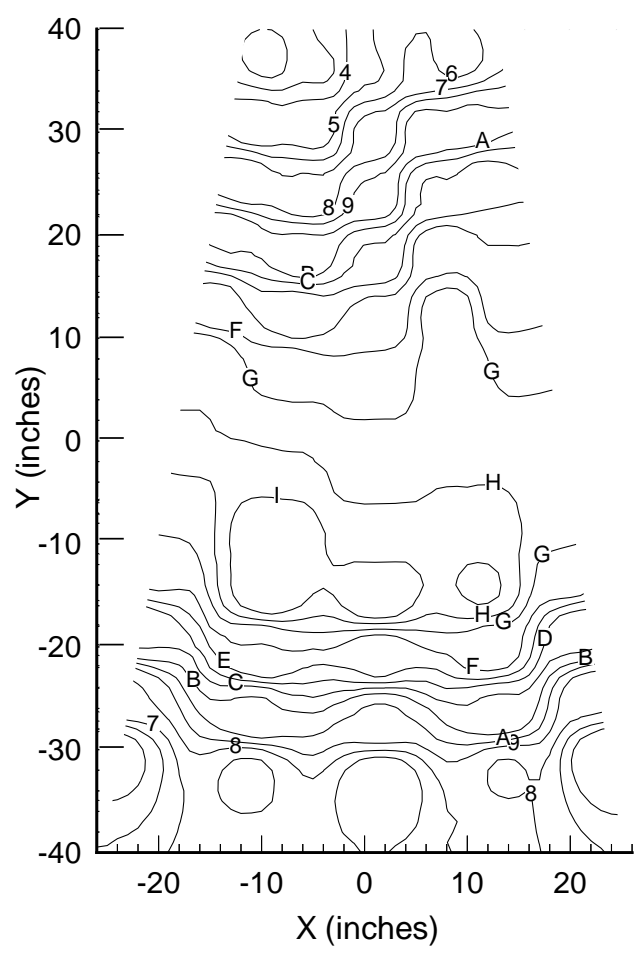

a. Pitot pressure.

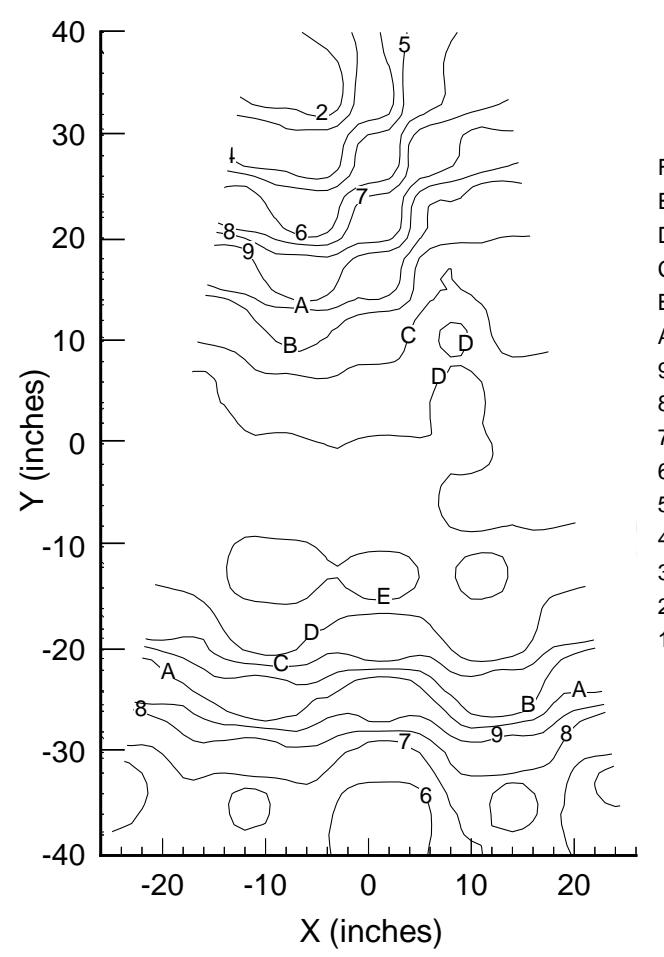

b. Total temperature.

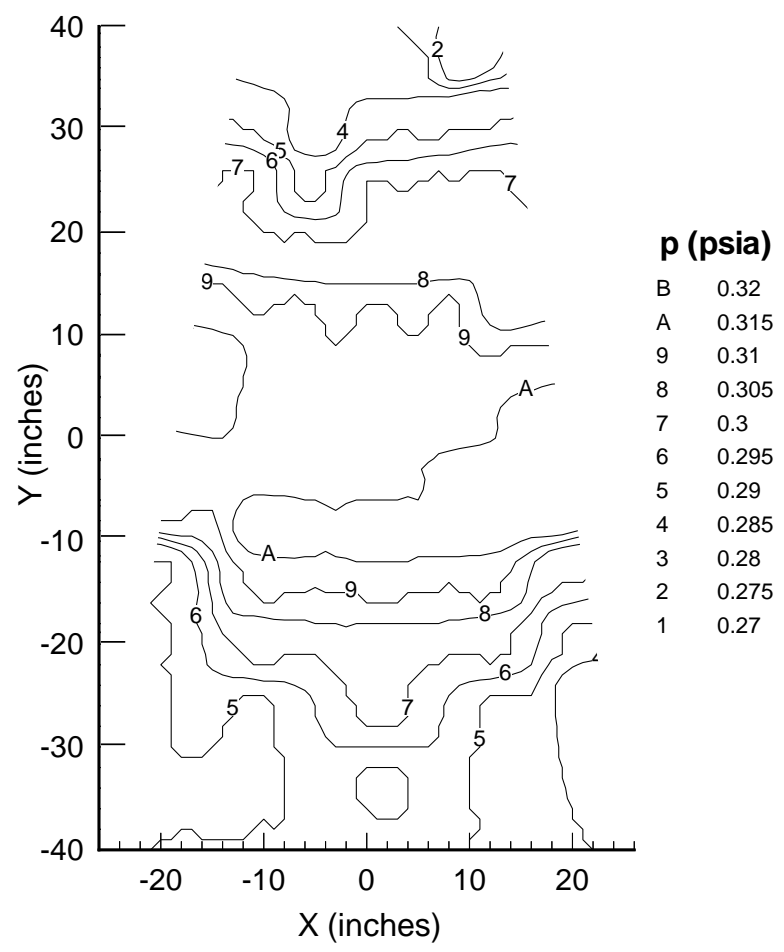

c. Static pressure.

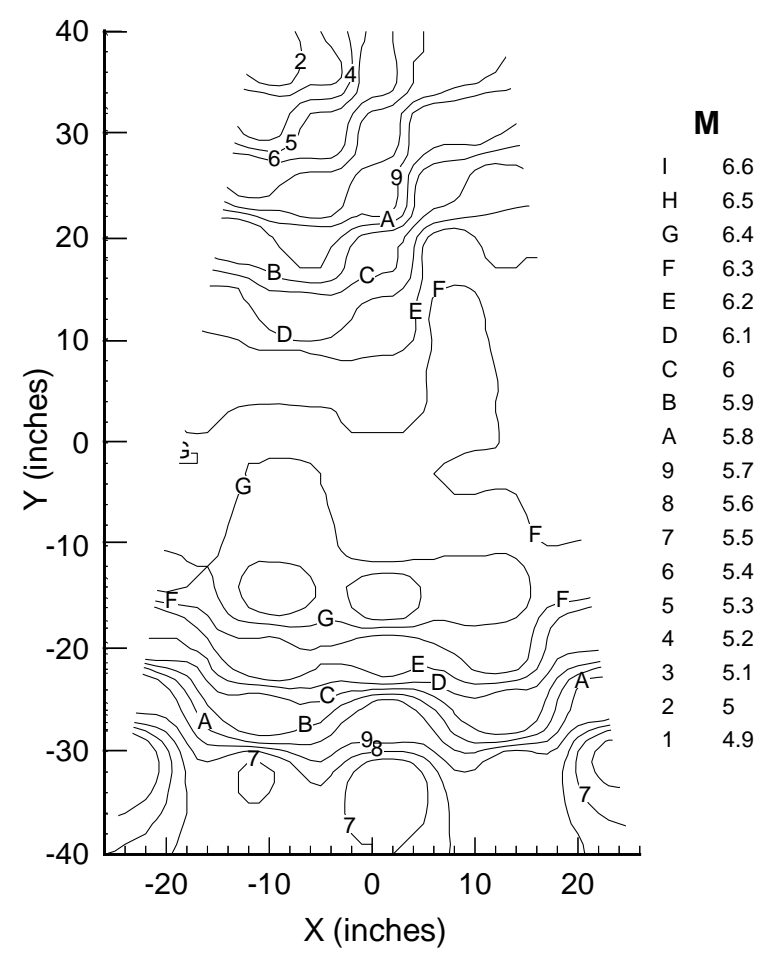

d. Calculated Mach number.

Figure 13. Contour plots of Mach 6.3 test core (looking upstream). 


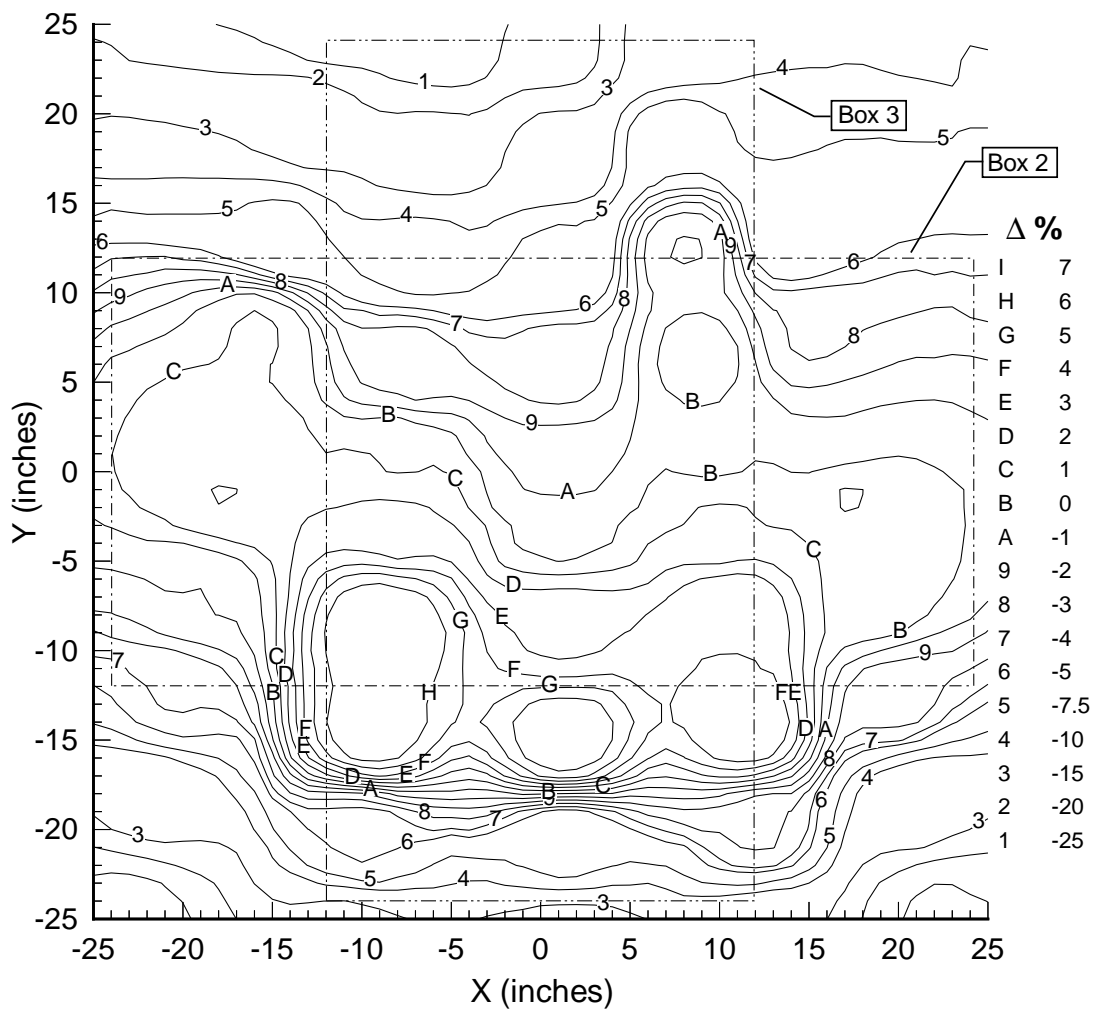

a. Pitot pressure.

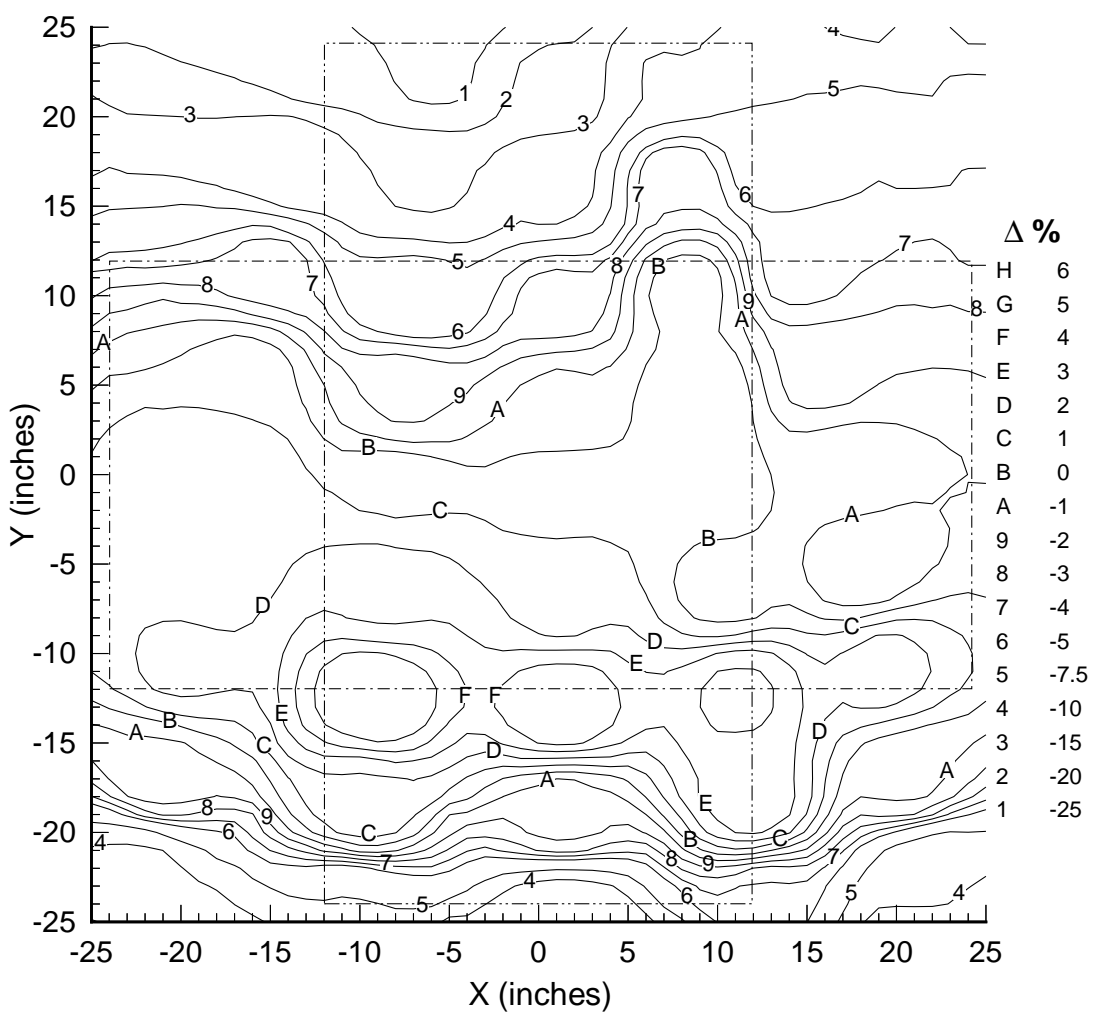

b. Total temperature.

Figure 14. Contour plots of Mach 6.3 test core percent deviation from stream thrust average (looking upstream). 


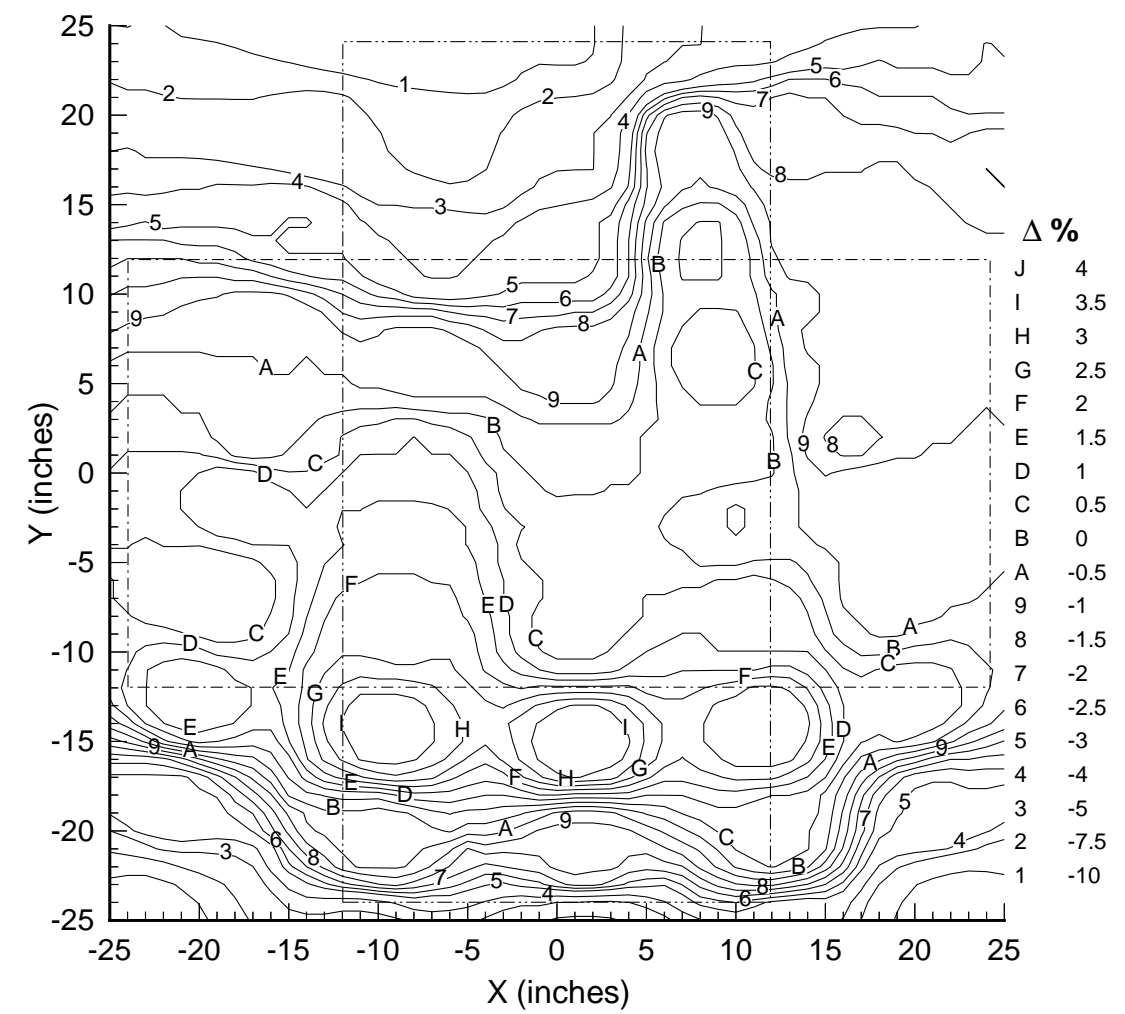

c. Calculated Mach number.

Figure 14. Contour plots of Mach 6.3 test core percent deviation from stream thrust average (looking upstream).

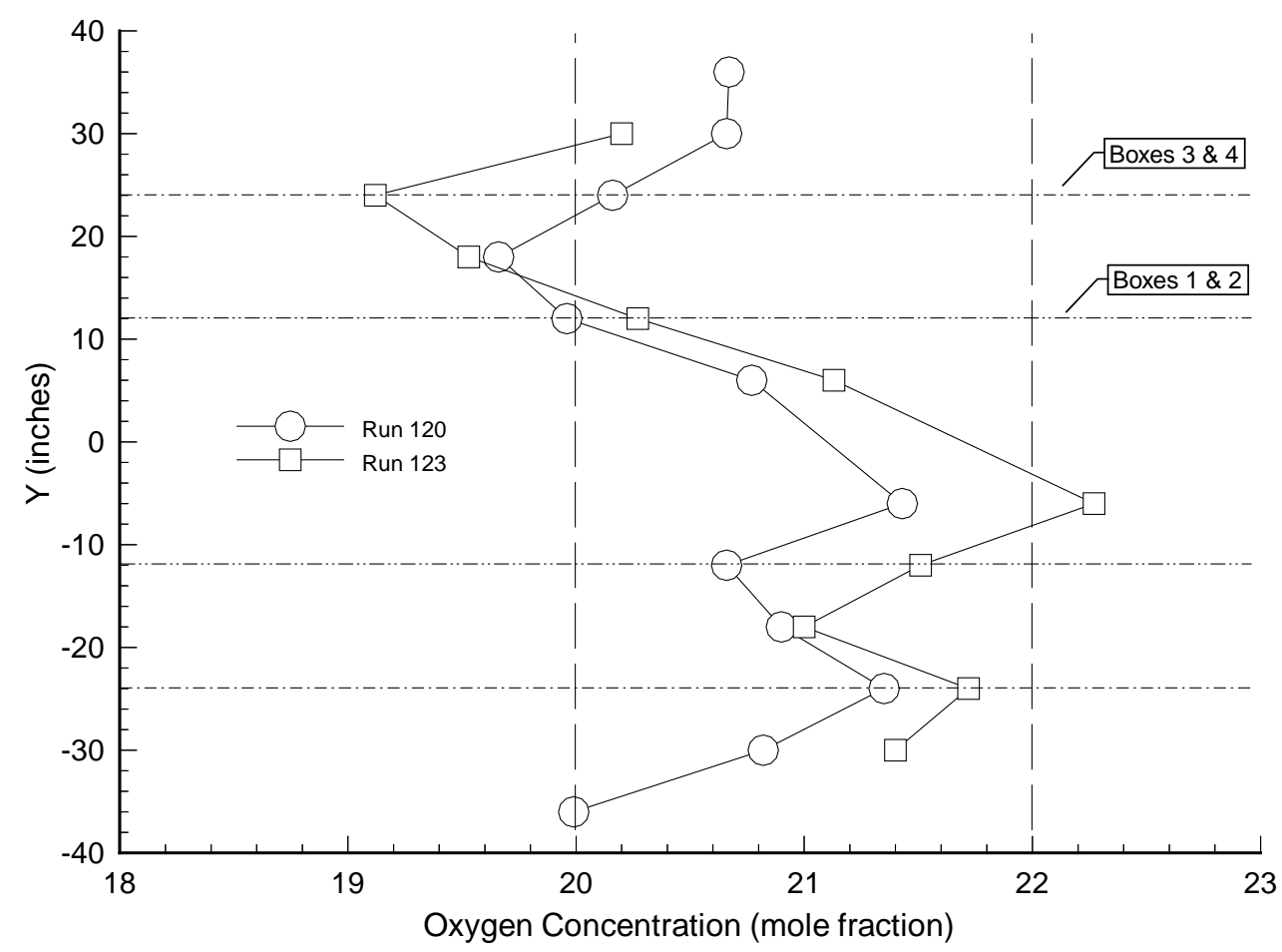

Figure 15. Mach 6.3 test core oxygen concentration measured on tunnel centerline. 


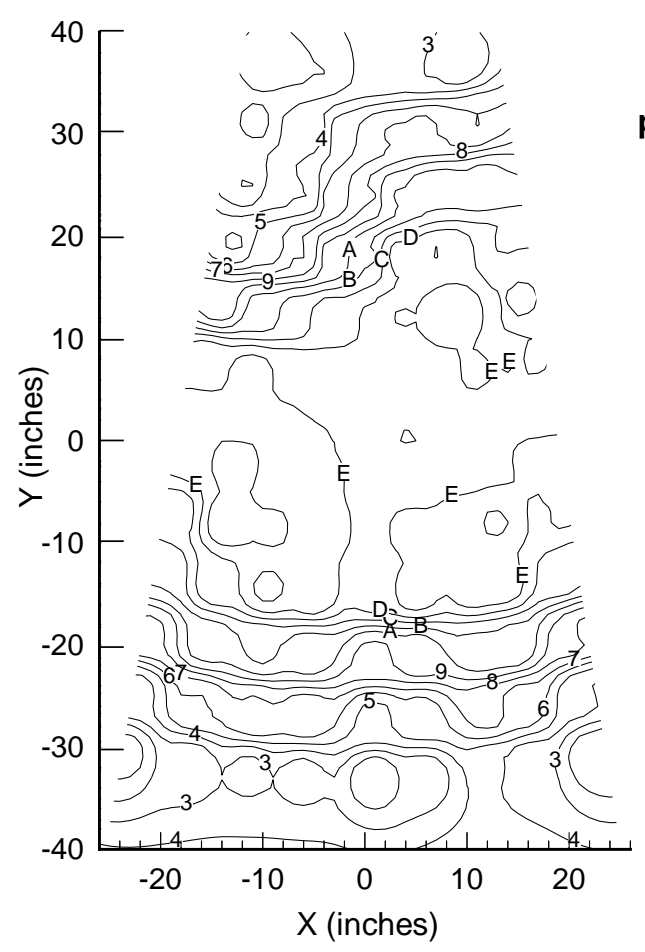

a. Pitot pressure.

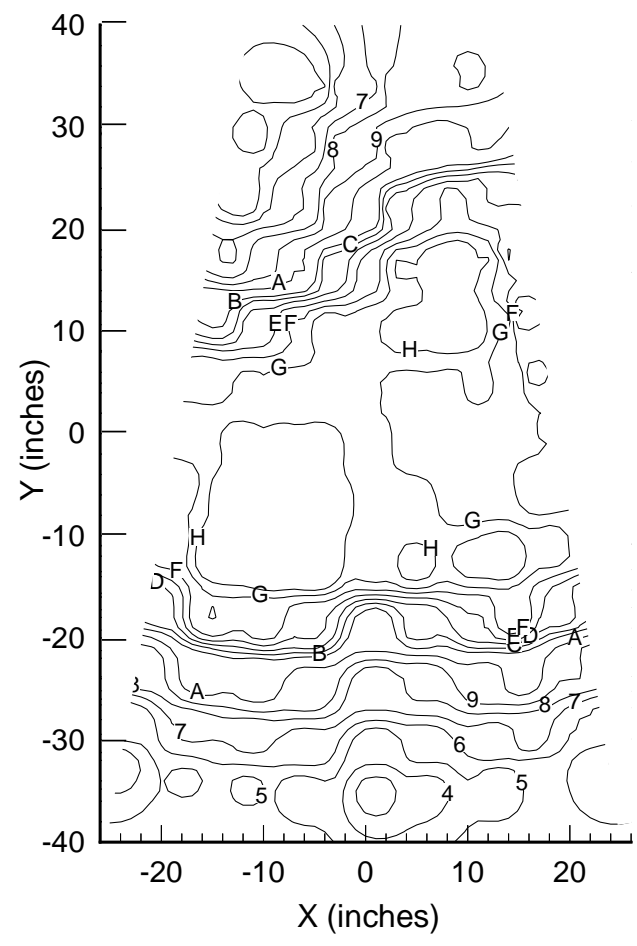

b. Total temperature.

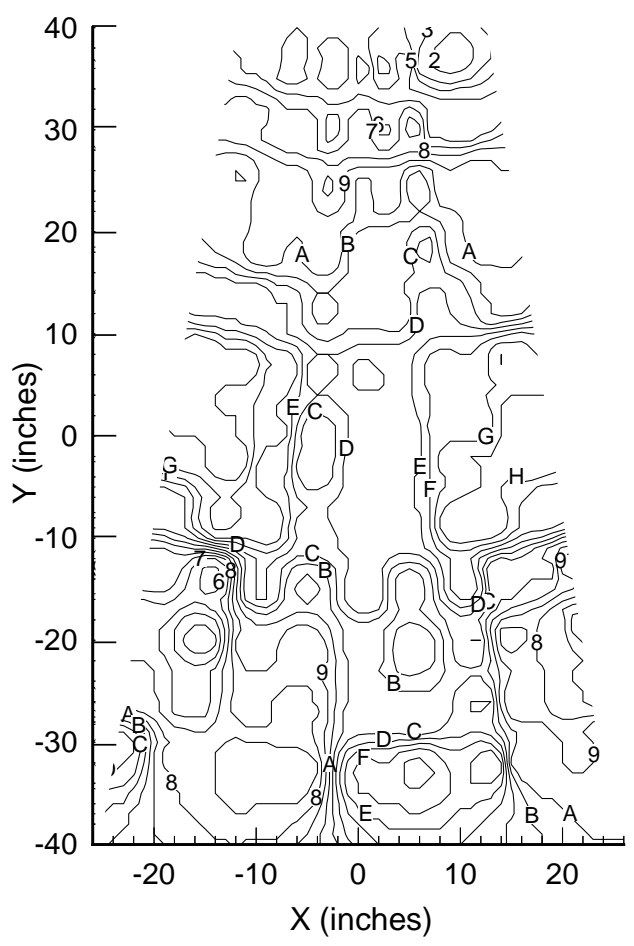

c. Static pressure.

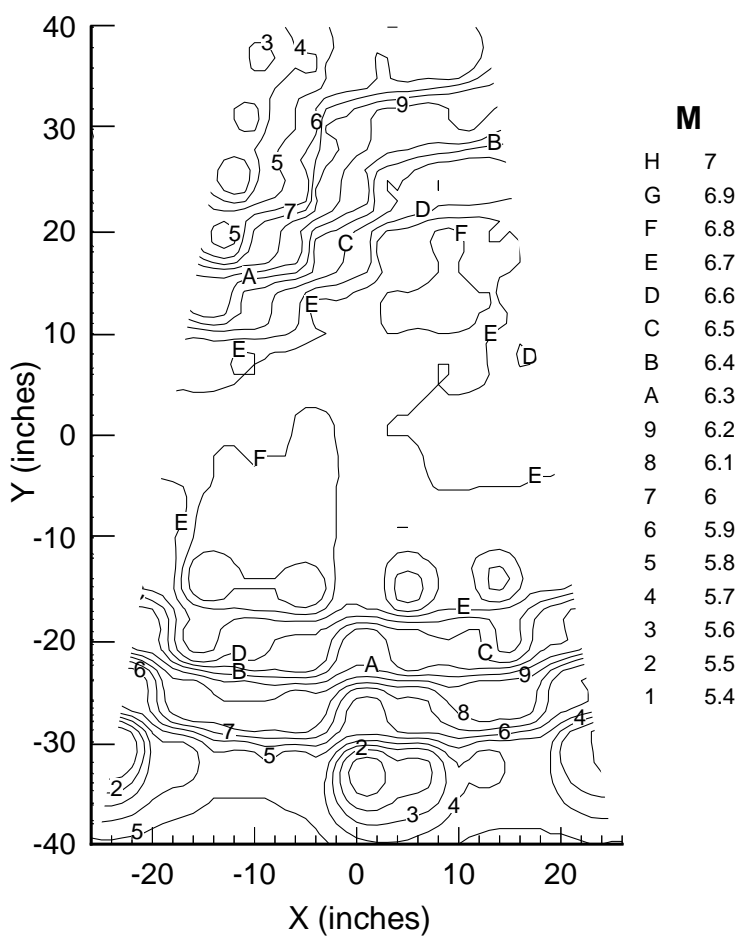

d. Calculated Mach number.

Figure 16. Contour plots of Mach 6.8 test core (looking upstream). 


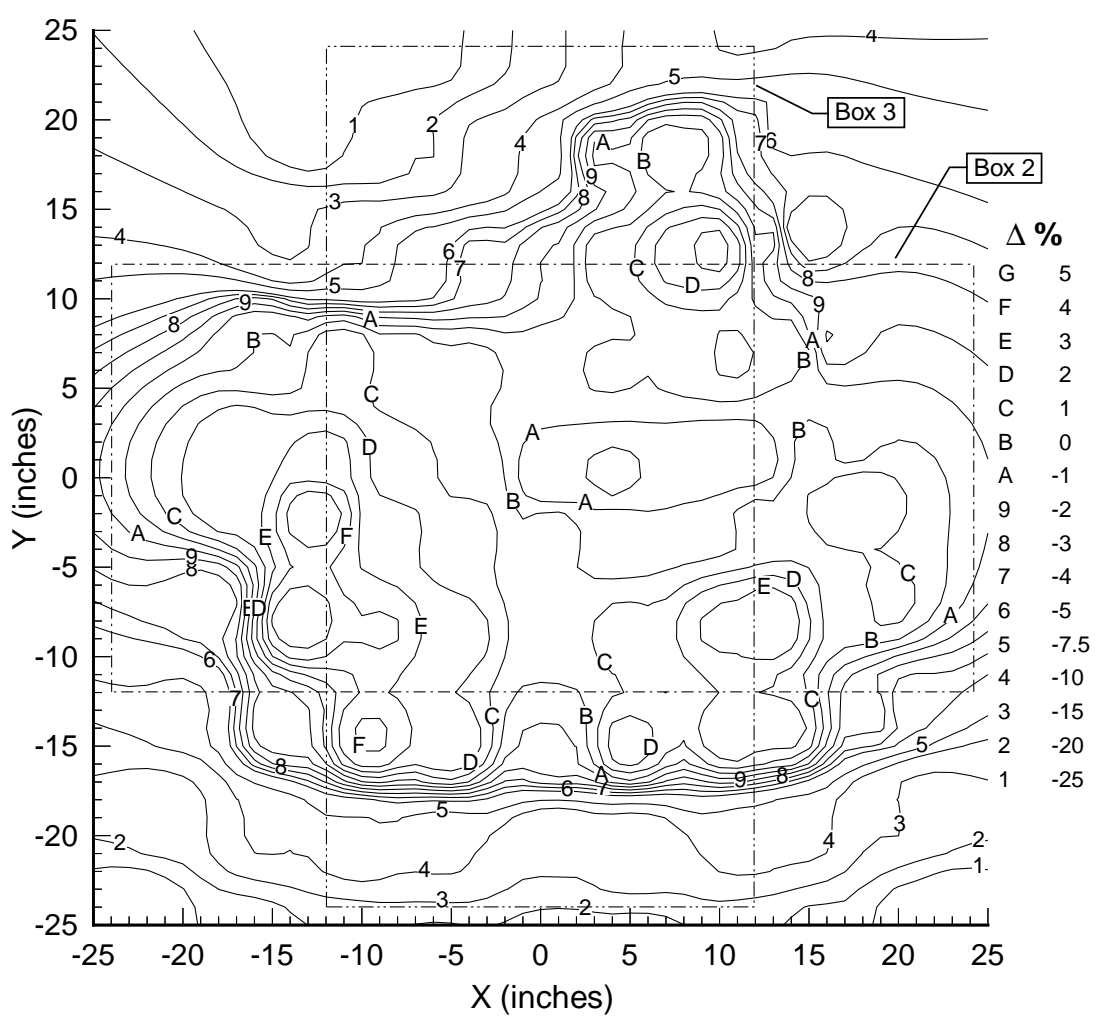

a. Pitot pressure.

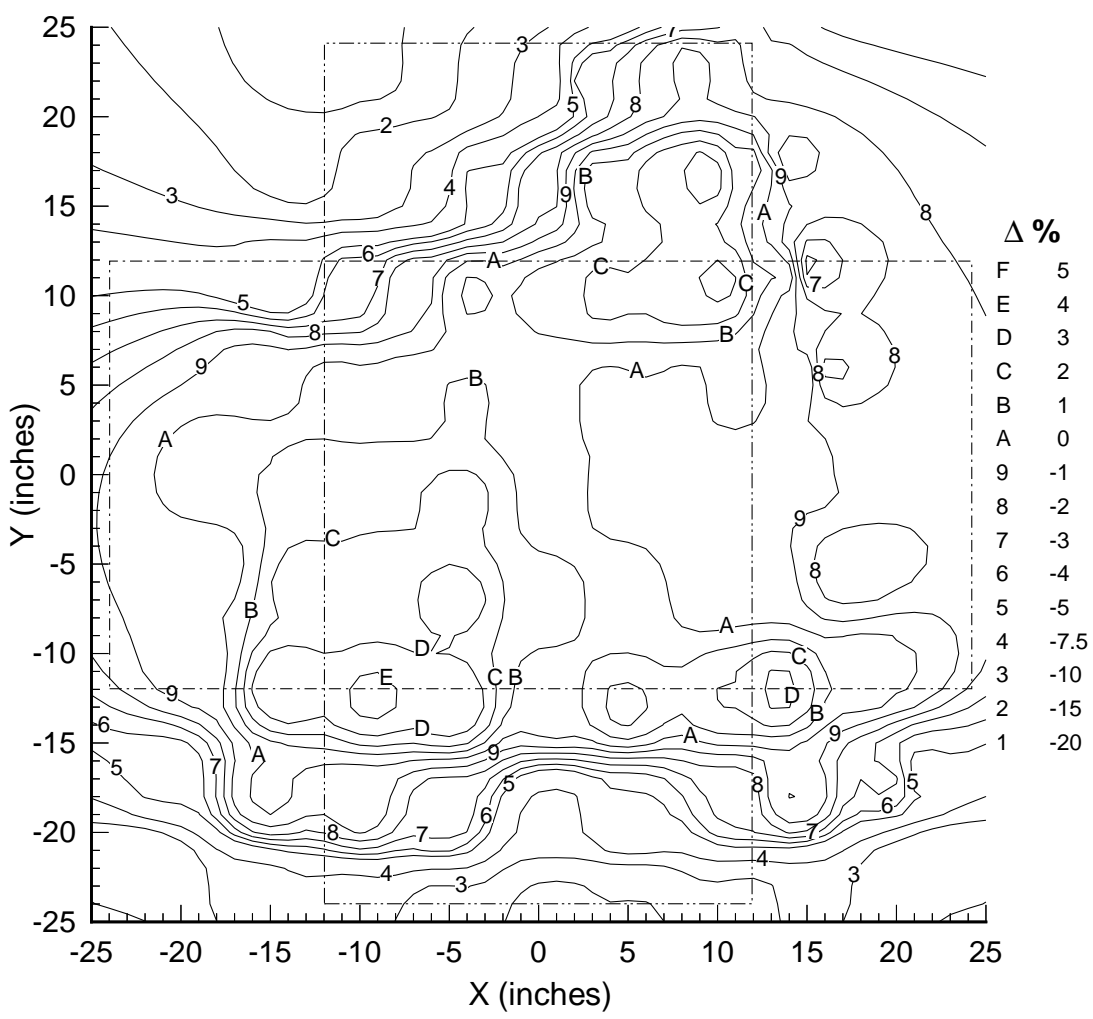

b. Total temperature.

Figure 17. Contour plots of Mach 6.8 test core percent deviation from stream thrust average (looking upstream). 


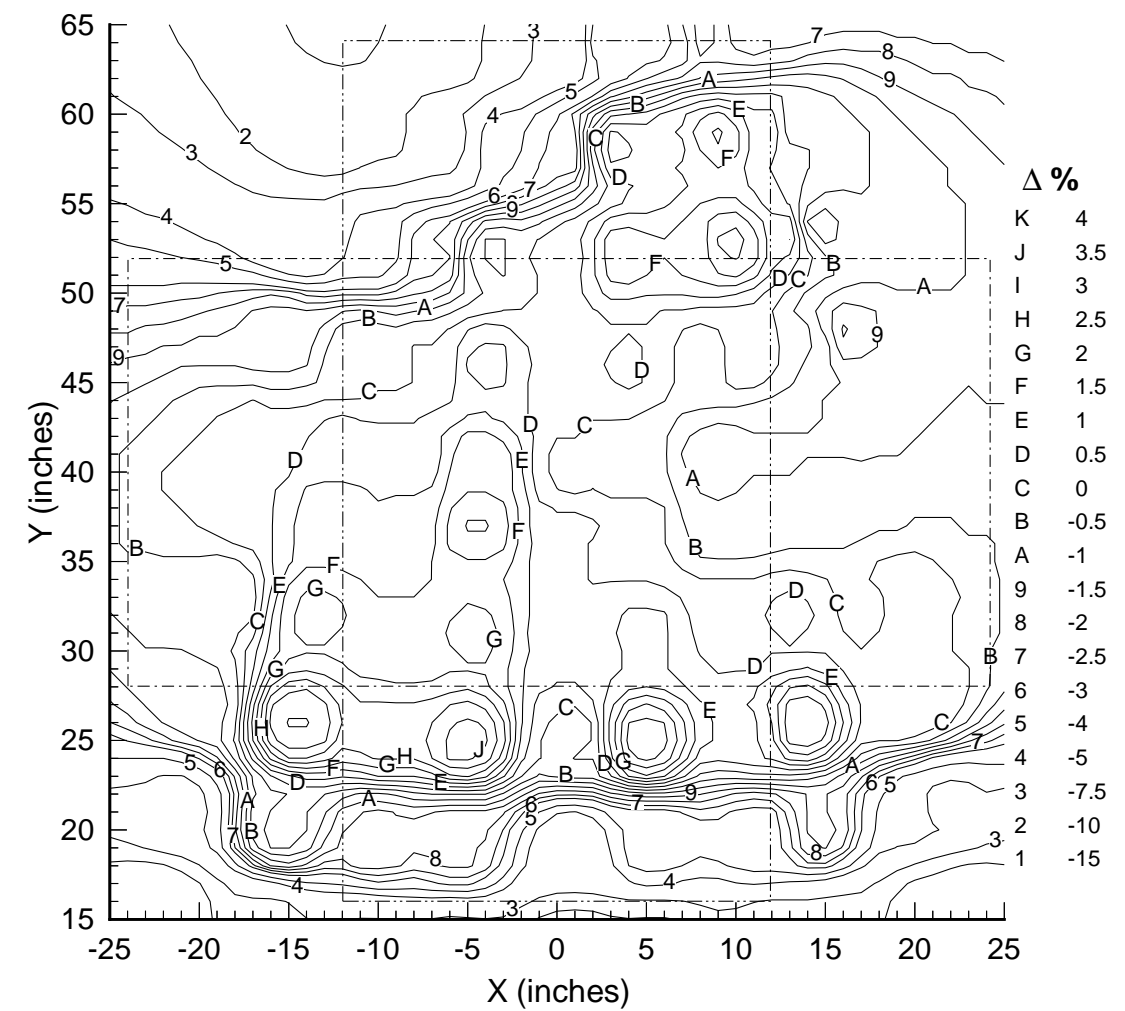

c. Calculated Mach number.

Figure 17. Contour plots of Mach 6.8 test core percent deviation from stream thrust average (looking upstream).

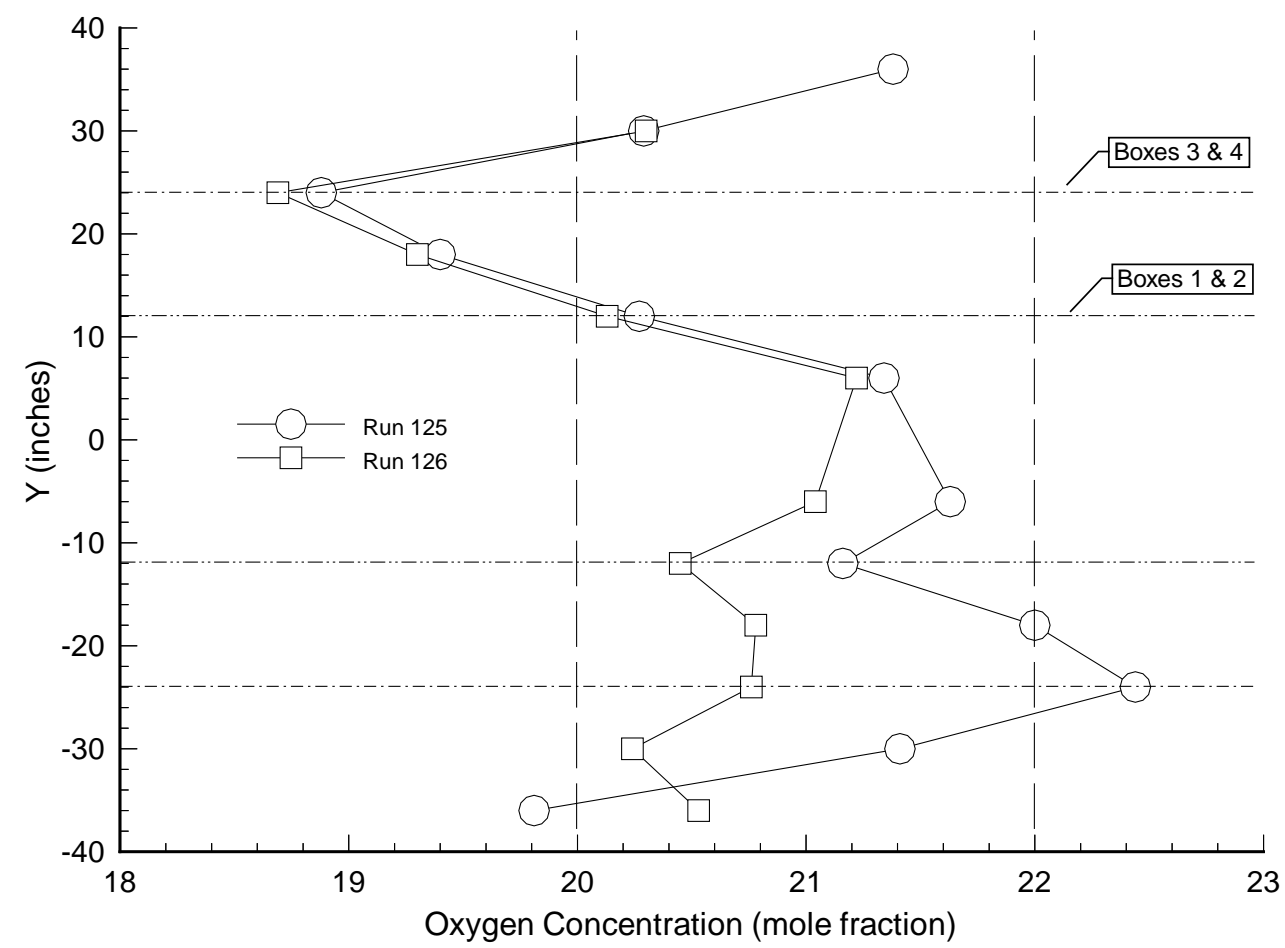

Figure 18. Mach 6.8 test core oxygen concentration measured on tunnel centerline. 